\title{
Metamorfose Corporal na Moda e no Carnaval
}

\section{Oliveira de Araújo, Carlos Roberto}

Resumo:

O objetivo deste artigo é apresentar um estudo dos desafios da forma nos corpos generizados encontrados na moda e no carnaval carioca. O corpo é um veículo essencial da existência humana em qualquer cultura e vem se tornando cada vez mais crítico no mundo contemporâneo. O ser humano existe e participa dos grupos sociais através de seu corpo.

Independentemente de seu gênero, o corpo é muito mais que um conjunto de músculos e ossos, é também a roupa e o estilo que o decoram, e a imagem que por meio dele é produzida; constituindo-se em permanente desafio para os profissionais da moda. O dualismo de sexo e gênero constitui uma dimensão

Cuadernos del Centro de Estudios de Diseño y Comunicación №76

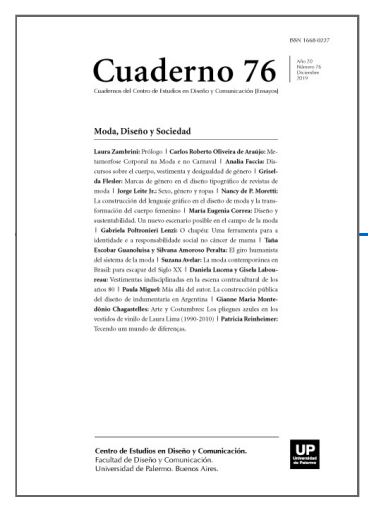

ISSN: 1668-0227

Moda, Diseño y

Sociedad

Año XX, Diciembre 2019, Buenos Aires, Argentina | 242 páginas

descargar PDF ver índice de la publicación

Ver todos los libros de la publicación

compartir en Facebook

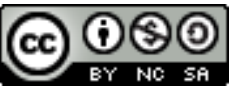
Esta obra está bajo una Licencia Creative Commons Atribución-NoComercialCompartirlgual 4.0 Internacional

crítica desses processos.

Palavras chave:

Corpo - Gênero - Moda - Carnaval - Metamorfose - Comunicação - Linguagem corporal.

(*) Graduado em Tecnologia em Produção do Vestuário (TPV) pela Faculdade SENAI/ CETIQT-RJ; MBA em História da Arte e Comunicação e Semiótica pela Universidade Estácio de Sá; Pós graduado em Figurino e Carnaval pela Universidade Veiga de Almeida. Docente e proprietário da Instituição CROA Modelagem; experiência profissional de mais de 20 anos no mercado de moda, como modelista especializado nos segmentos masculino, feminino, infantil, moda praia / fitness e drapping. Facilitador no Curso Design de Moda Praia no Instituto Europeu de Design Brasil - IED/RJ. Dedica-se também ao desenvolvimento de modelagem de figurinos de carnaval para várias Escolas de Samba do Rio de Janeiro (Grupos de Acesso e Especial), assim como de figurinos para teatro. Autor do livro Modelando moda praia - Técnica das três linhas, Editora Barra Livros - 2016. 
No carnaval e no mundo da moda é possível encontrar todos os gêneros, independente de classe social, na constante busca por corpos perfeitos, o que comporta ansiedade e expectativas muito superiores às da realidade corrente.

O ideal de corpo perfeito mudou muito nas últimas décadas. No início do século $\mathrm{XX}$, as mulheres fisicamente perfeitas mediam cerca de 1,60m e pesavam $63 \mathrm{~kg}$. Na década de 1940, as pessoas de corpo magro e ossudo eram vistas como nervosas, submissas e retraídas -nada atraentes, em suma (Cohen, 2015). Considerava-se que Marilyn Monroe tivesse, nos anos 1950, o corpo feminino perfeito -a chamada "silhueta ampulheta", também conhecida como "corpo violão", ou seja, aquela em que a circunferência do busto é mais ou menos a mesma do quadril e a circunferência da cintura é menor. Cohen (2015) lembra, porém, que já na década de 1980 a silhueta ampulheta ficou ultrapassada. As modelos passaram a ser magérrimas, e um grama a mais de gordura era -e é ainda atualmente- considerado uma tragédia. Há 25 anos atrás as top models e divas públicas da beleza pesavam $8 \%$ a menos do que a média feminina; agora pesam $23 \%$ a menos. Apenas $5 \%$ das mulheres atingem o que a indústria da alta costura e a mídia atualmente decretam como sendo o peso e a altura ideais1.

Nos últimos anos as mudanças corporais, sejam elas obtidas através das cirurgias plásticas, das academias, ou do uso de anabolizantes e outros recursos para atingir o objetivo desejado -almejam produzir um corpo bem trabalhado, sem as marcas indesejáveis do tempo e sem excessos de gordura e flacidez.

A antropóloga Mirian Goldenberg, em seu livro O corpo como capital (2010), questiona: "Se o corpo é a imagem social, que sociedade está representada nos corpos dos brasileiros?". A autora tem refletido, na última década, sobre que modelo de corpo tem prestígio na cultura brasileira e qual é o modelo de corpo desejado ou imitado pelas mulheres - e também pelos homens. O corpo que é considerado valorizado, invejado, admirado pode ser também objeto de desejo e fonte de felicidade e a chave da porta de entrada para a vida profissional tão desejada no mundo da moda e no carnaval para qualquer ser humano, independentemente de gênero ou classe social. O binarismo entre sexo e gênero é um exemplo disso, de modo que a polêmica entre essencialismo (o corpo está dado na natureza) e construtivismo (o corpo é produzido na cultura) é delicado para o desenvolvimento desse tema, no que tange à compreensão do corpo como "produto cultural" e às consequentes sugestões na construção do binarismo sexual2 .

Com a tão esperada metamorfose, o indivíduo passa a ter uma nova linguagem corporal: maneiras de andar, de falar, de cumprimentar, de se vestir, etc. Somente as mulheres tinham anteriormente essa preocupação visível: a deter um belo corpo, de estar bem vestida e de apresentar uma bela face. Hoje, os homens, metrossexuais ou não, também passaram a tornar visíveis seus esforços em se metamorfosear, por meio de novos recursos de se vestir e embelezar.

Generalizou-se assim uma verdadeira neurose em todos os gêneros sobre a própria beleza e apresentação social, para criar uma nova impressão e uma identidade comercial eficiente através da nova forma, utilizando-se de vestuário, etiqueta, comunicação, linguagem corporal e habilidades de protocolo.

Sobre o intumescimento3 característico dos machos de diversas espécies animais, Cohen (2015) explica: 
Quando um sapo quer impressionar os outros sapos, ele se intumesce. Os homens fazem a mesma coisa. Nós exageramos o peito e a amplitude dos ombros, e é por isso que os uniformes militares e os ternos comerciais são talhados de forma a aumentar o nosso perfil. Algumas espécies, como os gatos, cães e leões, espicham o pêlo para intimidar os outros. [...] Nós, ao contrário, vamos a um bom cabeleireiro para melhorar a aparência do cabelo, o que dá a impressão de estarmos no controle. (Cohen, 2015, p. 103)

O que é perceptível no corpo contemporâneo, após a colocação de próteses de silicone nas mamas ou nas nádegas, lipoaspiração e retoques cirúrgicos, é que a linguagem corporal apresentada é uma forma de enfatizar o ponto do corpo metamorfoseado. Ora a mulher passa a não fazer mais uso do sutiã 4 -o que pode ser considerado o ápice da ostentação do corpo feminino; ora o abdômen negativo5 é exibido com o uso de blusas hiper curtas; ora o bumbum é que é exibido com shorts mínimos e calças bem coladas ao corpo.

Para o homem, em sua conquista corporal -que pode ser obtida com os mesmos recursos femininos- os pontos mais cobiçados são o aumento do peitoral e do bíceps e a boa definição do abdômen. Com o aumento do tórax, passa-se a dar ênfase à ausência de camisa ou ao seu uso bem justo ao corpo; o andar toma a forma do movimento de "avião" -exagerando o peito e a amplitude dos ombros pela estratégia de jogá-los para a direita e a esquerda- e o bíceps pode ser destacado com o uso de tatuagens. Há grande preocupação no gênero masculino em aumentar os ombros e afinar a cintura, mas é comum os membros inferiores serem menos desenvolvidos, formando a silhueta do triângulo invertido6. Essa silhueta é a preferida pelos carnavalescos ou diretores de carnaval para ocupar a posição de destaque nos carros alegóricos, por ser considerada a mais erótica, sexy, atraente.

Na espécie humana, como entre os sapos e os leões, também está presente a necessidade de reconhecimento pelos semelhantes, mas ela se manifesta de forma mais complexa, mediada pelos recursos simbólicos de cada cultura. Todo ser humano depende de uma avaliação interpessoal da aparência visual e comportamental, de uma observação (mú- tua) dos pés à cabeça de seus semelhantes, a respeito de sua linguagem corporal, de sua apresentação social e dos acessórios de que se reveste o seu corpo. Como diz o ditado, "a primeira impressão é a que fica". Para atingir algum objetivo social com uma nova forma, é preciso avaliar e identificar a sua nova personalidade, sua aparência física e o seu lifestyle. E, sobretudo, avaliar como essa apresentação pública de si mesmo repercute entre os circunstantes e interlocutores.

Goldenberg (2005) afirma que:

O final do século XX e o início do XXI serão lembrados como o momento em que o culto ao corpo se tornou uma verdadeira obsessão, transformando-se em um estilo de vida, pelo menos entre as mulheres das camadas médias urbanas" (2005, p. 66).

\section{O corpo na moda}

Para uma mulher ser aceita no mundo da moda7 como modelo, é preciso estar dentro de um "padrão" desejado pelos estilistas, editores e produtores de moda. Ser alta não basta, tem que saber se produzir, ter linguagem corporal própria e fazer "carão". Os padrões podem mudar de acordo com a época para iniciar a carreira de modelo. A idade indicada para começar a modelar fica entre 14 e 18 anos para as meninas, e entre 16 e 20 para os rapazes, quando os corpos adquirem as características desejadas a serem desenvolvidas. Para todos os 
gêneros diversas medidas corporais ideais devem ser respeitadas: altura geral; largura de busto, cintura e quadril, e comprimento das pernas (Figura 1).

Os homens, por sua vez, devem apresentara tal silhueta do triângulo invertido - ombros largos; cintura, coxas e pernas finas.

Todos os modelos devem ter a preocupação de manter uma dieta balanceada e uma rotina de exercícios físicos que priorize a tonificação muscular. O corpo masculino, por ser mais reto, é mais simples que o feminino para vestir, mesmo depois de passar por algum tipo de metamorfose corporal.

Analisando editoriais de moda, desfiles e o universo fashion, pode-se concluir que o corpo ideal é, curiosamente, aquele que vai se comunicar com uma aparência considerada como "natural", podendo ser considerado equilibrado, sem exageros musculares ou o uso de outros evidentes e pesados artifícios de beleza. O problema reside justamente no que a cultura vai definindo como "natural" em cada sociedade e em cada época.

Constantemente temos notícias, através das mídias especializadas em moda, de casos de modelos que deixam de comer para ficarem magras, tendo como referência uma modelo top, enquanto que outras com o corpo considerado fora do "padrão" sentem-se frustradas e gordas por não conseguirem o padrão magricela e esquelético8 . As modelos estão sempre em busca do corpo perfeito, e quando o objetivo não é alcançado pode se seguir até um óbito por desnutrição ou suicídio (Figura 2).

Os anos de 1990 investiram no que é chamado de moda "conceito" ou de moda "álibi". Tudo passou a ser disputado na passarela. A subjetividade tornava-se celebração móvel. O deslocamento dos valores da personalidade acentuou progressivamente a importância do capital cultural corporal. A moda passou a ser lugar de investimento importante no processo de subjetivação e não apenas, uma confirmação de um sujeito pronto e pleno, sugerindo comportamento e atitudes (comunicação corporal), fabricando selfies performáticos por meio de perspicazes recriações dos conceitos de verdade, de bem e do belo (Villaça \& Castilho, 2006).

Sobre o "corpo capital" Villaça \& Castilho observam que:

Não sendo acultura feita de necessidades, a moda, o mercado e seus intermediários lançam sinais que são efetivamente legitimados por uma cooperativa de consumidores, segundo Zygmund Bauman, em "O mal-estar da pós-modernidade", enfatizando os que usam e atribuem significados aos sinais, sugerindo um "ar do tempo", uma agenda fashion. Aumenta o cuidado com o corpo, incessantemente esculpido por lipoaspiração ou próteses de silicone.[...] O corpo torna-se capital, cercado de enormes investimentos de tempo, dinheiro. O corpo "em forma" é signo de sucesso pessoal, ao qual qualquer mulher ou homem pode aspirar se realmente se dedicar (Villaça \& Castilho, 2006, p. 10).

Em 2015, dois decretos publicados no diário oficial francês, segundo o site www.folha. uol.com.br, impuseram regras para combater a anorexia no meio da moda e coibir o retoque das imagens publicadas da silhueta das modelos. As regras valem para manequins de outros países europeus que exerçam a profissão na França. As infrações poderão ser punidas com pena de prisão e multa de até $\mathrm{R} \$ 262$ mil. A medida faz parte de um combate mais amplo contra a anorexia, apoiado pelo presidente François Hollande. Parlamentares também aprovaram uma outra medida separada tornando ilegal a promoção pública da anorexia, com alvo nos sites que 
encorajam perda de peso em níveis perigosos. Para completar as novas regras, os retoques fotográficos com fins comerciais deverão ser sempre claramente indicados9 .

Atualmente há grande discussão sobre o uso excessivo de softwares de edição de imagens pela mídia. São divulgados ideais de beleza inalcançáveis, em fotos editadas que chegam até a modificar a silhueta dos modelos ou das celebridades que estampam campanhas publicitárias e revistas de moda. Quem estampa tais campanhas e editoriais são, na maioria das vezes, modelos demasiadamente magras. Graças aos retoques, estabelecem-se padrões que impregnam o imaginário coletivo com o desejo de ter aquele "corpo perfeito".

No mundo da moda, beleza, corpo perfeito e atitude andam juntos. Além de criar tendências, as marcas precisam mostrar que estão acompanhando o que há de mais avant-garde10 quando o assunto é comportamento. Eli Wahbe, fundador da agência Mega Model, declarou à Folha de São Paulo11 que a moda vai se tornar cada vez mais inclusiva. "Há dois anos, falam mais de personalidade que de biótipo. (...) A gente é prestador de serviço".

Um segmento social de crescente visibilidade, em que o tema da personalidade prevalece, é o que compreende as pessoas transgênero. Ainda assim, como é cobrado aos aspirantes à carreira de modelo no mundo da moda, também aos transgênero será exigido dar conta da luta para conseguir o "corpo perfeito" -chave da porta de entrada para o mundo da moda- a marca dos devidos esforços para obter o biótipo adequado para as criações dos estilistas.

No site www.epoca.globo.com, o jornalista Bruno Astuto, sobre o desfile da marca do estilista Amir Slama, em 2017, escreve em sua coluna: "Valentina Sampaio foi a primeira transexual a desfilar para uma grife de moda praia na história da semana de moda paulista". Ao jornalista o estilista Amir Slama fez coro:

Modelo trans, modelo isso ou aquilo, não importa. Quando faço o casting não levo essas questões em consideração. Aliás, só fui saber depois que a Valentina era trans. Para mim ela é uma ótima modelo, linda, com um corpo incrível e ponto final. É isso o que interessa, elogia Amir.

O jornalista completa que Valentina Sampaio foi ainda a primeira trans a estrelar a capa da quase centenária Vogue Paris (Figura 3), e também a primeira trans a desfilar moda praia na história da São Paulo Fashion Week (Figura 4), abrindo e encerrando o desfile -e sublinha o quanto este fato é sinônimo de prestígio no mundo da moda.

A modelo Valentina Sampaio, em entrevista ao jornalista Bruno Astuto relata: "Lutei para estar aqui, para ser modelo. E tudo o que tem acontecido na minha vida é resultado desse esforço. Sei que não estou aqui pela minha condição, mas porque tenho capacidade para trabalhar nesse meio", diz ela.

O estilista Ronaldo Fraga, segundo o site www.vogue.globo.com, apresentou em seu desfile-manifesto de 2016, um casting $100 \%$ trans, no qual pediu respeito aos transexuais, com apresentação poética e emocionante no São Paulo Fashion Week (Figura 5).

A identidade de gênero tem muito mais a ver com a maneira como a pessoa se vê do que com a genitália que ostenta. A partir daí, se utilizam dois termos: transgênero (pessoa que não se identifica com as características do gênero designado no nascimento) e cisgênero (pessoa que se identifica com as características do gênero 
designado no nascimento). A identidade de gênero tampouco tem a ver com a orientação sexual. Há quem se identifique com o gênero feminino e se sinta atraída por pessoas que também se identificam com o gênero feminino e pessoas que se identificam com o gênero feminino e, ao contrário, se sentem atraídas por pessoas que se identificam com o gênero masculino; logo, identidade de gênero semelhante e orientação sexual totalmente diferente.

Todas essas possibilidades de identificações de gênero e de orientações sexuais não convencionais abrangem um número considerável de pessoas. Existem as identidades não-binárias (ou genderqueer no inglês), que não se sentem confortáveis em uma divisão entre gênero masculino e gênero feminino. Talvez não se importem com isso; talvez se sintam atraídas por outras pessoas independentemente da identidade de gênero, num registro não-binário12. O gênero binário (Reis \& Pinho, 2005) se manifesta quando os corpos são pontos de convergência no binarismo nas diversas áreas e saberes da sociedade. As principais características secundárias de corpos femininos e masculinos são a distribuição de pelos, a presença de seios e a circunferência do quadril, que passam a determinar o que é ser homem e ser mulher para cada área. A mídia poderá, através de produções audiovisuais recorrentes, reforçar diferentes características ditas essenciais e específicas para ser homem -como virilidade física e racionalidade-e, assim, construir num campo simbólico o que significa efetivamente se considera ser homem. Os autores completam narrando que essas constru- ções não permanecem no campo simbólico, mas extravasam para a construção da materialidade dos corpos. Os homens poderão, por exemplo, frequentar academias de ginástica para desenvolver sua massa muscular, pela questão estética, o que daria forma ao desejo simbólico. Essa incorporação reforça a virilidade como característica masculina e auxilia na produção de outras, como a habilidade em certos esportes ou a maior resistência às atividades físicas -se comparada à das mulheres.

Sobre o corpo masculino Machado (2010) analisa:

O corpo masculino é um corpo apagado naquilo que é mais próprio, um corpo sem sensibilidade, um corpo castrado na expressão livre dos efeitos trazidos pelos afetos das coisas e das pessoas. É um corpo domado, enrijecido, construído como uma carapaça muscular, que visa a protegê-lo do mundo exterior.[...] O corpo masculino é pensado como um corpo instrumental, um corpo a serviço de si mesmo, auto-controlado, autocentrado, auto-erotizado, autista, fechado, travado. O corpo masculino teme a fuga, teme o desejo, teme o afeto, teme tudo que o possa arrastar para fora de si mesmo, possa gerar o descontrole, a abertura, a fragmentação, a viagem. Corpo pensado e treinado para se defender, para dominar a si mesmo e a outros, corpo treinado para ser reativo a tudo que vem de fora, corpo reacionário. Corpo adormecido, corpo censurado, corpo anestesiado, corpo pânico. O corpo masculino pensado e modelizado pela cultura judaico-cristã, pela cultura burguesa, é um corpo censurado e instrumental, um corpo docilizado, um corpo com medo de corpos. (2010, pp. 25 -26)

Alguns cientistas italianos afirmaram recentemente, segundo Machado (2010), que a espécie humana caminha para a androginia13, para as sexualidades múltiplas, para a quebra dos papeis de gênero antes consagrados pela sociedade.

Coco Chanel, no início do século XX, libertou as mulheres dos espartilhos e usou o traje de marinheiro como referência para oferecer às suas clientes roupas com estilo esportivo; a androginia tornando-se progressivamente uma tendência possível na moda. O estilista Yves Saint Laurent daria seguimento à tendência criando "le smoking" -versão feminina do convencional traje formal masculino- e chocando o mundo 
conservador dos anos 1960, quando as mulheres ainda eram mal vistas ao usar calças compridas. A ousadia quebrou paradigmas. Mas os plenos frutos da moda andrógina só viriam a amadurecer em 2015. A tradicional figura da noiva que encerra as apresentações da Maison Chanel subiu à passarela encarnada por Kendall Jenner (Figura 6), usando terno e penteado masculinos. Um poderoso rompimento! Não fosse o véu, olhos destreinados poderiam ter confundido a noiva com um noivo; nesse momento em que os limites entre feminino e masculino eram mais claramente desafiados.

A identidade de gênero é um assunto muito complexo e delicado. Há especificidades em cada termo; há quem não goste de ser rotulado com uma mera palavra; há os intersexuais -pessoas cuja anatomia não se encaixa no padrão macho/fêmea, o que um dia já se chamou de hermafrodita- e há quem não se identifique com nenhum desses termos e prefira utilizar novos. A melhor maneira de se aproximar da identidade de gênero que caracteriza cada indivíduo é certamente a da auto-identificação em cada momento da interação social.

Tem cabido ao sistema internacional da moda acolher essa flexibilização das identidades de gênero, permitindo a cada pessoa enveredar pela melhor expressão de sua auto- -identificação, com os melhores rendimentos estéticos e os menores custos psicológicos e culturais.

\section{O corpo no Carnaval}

É uma festa que encanta o mundo inteiro, em que todos os gêneros, com seus corpos seminus, são um espetáculo à parte, exibindo quase sempre as tais silhuetas perfeitas, corpos modelados e esculturais.

$\mathrm{Na}$ Cidade do Samba Joãozinho Trinta, no Rio de Janeiro, realizei trabalhos de modelagens de figurino de carnaval, no ano de 2013 na Escola de Samba Acadêmicos do Grande Rio, no ano de 2014 na Unidos de Vila Isabel, Grande Rio e Caprichosos de Pilares, e no ano de 2015 na Império Serrano (sendo as duas últimas pertencentes ao chamado "grupo de acesso", segunda linha na hierarquia das Escolas). Nesses locais de trabalhos foi possível perceber as mais diferentes formas corporais, independentemente do gênero, e, o que o componente, sendo celebridade ou não, é capaz de fazer para ter ou estar em um lugar de destaque na Escola, particularmente aquele que é o preferido e mais disputado: o carro alegórico. Quando escolhido para ocupar algum lugar de destaque na Escola, o carnavalesco ou o diretor de carnaval, faz uma avaliação à forma corporal e alerta: Vamos dar uma melhorada nesse corpo. Vai malhar para fazer bonito na Avenida! Essa frase é dita para qualquer componente, independente de ter ou não o corpo perfeito. O primeiro pensamento do componente é o da adequação ou não de seu corpo, e vêm as perguntas relacionadas com a obrigação de apresentar na Avenida um corpo impecável: Irei dar entrevistas para as redes de televisão? Serei convidado para a capa de alguma revista? O que fazer para ter o corpo mais perfeito na Avenida: cirurgia ou malhação?

Todos atribuem uma enorme importância a essa oportunidade de ser bem visto na passarela, por se tratar, literalmente, de uma passarela para a fama. Os postos mais desejados pelas mulheres são os de rainha de bateria, destaque de chão e destaque no carro alegórico14. Os homens cobiçam exibir seus corpos atléticos sobre os carros alegóricos.

Em 1985, a Escola de Samba Mocidade Independente de Padre Miguel, do Rio de Janeiro, deu início à novidade do cargo de "rainha de bateria" - convidando para a posição a então modelo Monique Evans (Figura 7), considerada na época dona de um corpo encantador15. O seu desempenho na função ao longo daquela década 
virou um símbolo de beleza e ousadia. Foi uma das precursoras do topless e do silicone nos seios, que logo depois viraram moda (Alzer, 2004).

Luma de Oliveira (Figura 8) foi outra modelo que, no carnaval de 1987, fez caírem os queixos masculinos de todo o país, ao desfilar deslumbrantemente como rainha da bateria da Escola de Samba Caprichosos de Pilares, com os seios à mostra. No mesmo ano posou para a Playboy, e estreou como atriz em uma novela televisiva, fechando a temporada com a eleição em Hong Kong para Miss Playboy Internacional, aparecendo nas capas de revista do mundo inteiro (Alzer, 2004).

A posição de rainha de bateria aos poucos foi sendo adotada na maioria das Escolas de Samba, tanto do Rio de Janeiro como de São Paulo. As Escolas passaram a contar com mais esse elemento de beleza a ser avaliado individualmente, encaixado no quesito "alegorias e adereços". A fantasia e o seu desempenho são avaliados durante o desfile, a rainha de bateria deve comandar a percussão e animar os componentes, o que gera grande expectativa e uma grande disputa para ocupar o cargo.

Em entrevista ao site www.g1.globo.com, sobre o posto de rainha de bateria, Monique Evans revela que:

Cobravam tanto da gente que era uma coisa quase profissional. A gente podia estar perfeita, mas a pressão era tão grande que quando acabava a gente ficava exausta. Parecia um trabalho. Aquilo cansava muito. Era pra ser uma diversão. Hoje em dia não acho que é mais isso. É uma maneira de as meninas aparecerem. É um trabalho pra elas, que vai trazer outros trabalhos no futuro. Pra gente não. Eu, depois a Luiza (Brunet) e a Luma (de Oliveira) já éramos famosas. Já trabalhávamos o ano inteiro e ainda tínhamos aquilo ali. ĺamos representar as nossas escolas mesmo. Era muita coisa que tínhamos que fazer e não tinha tantas regras. A bateria por si já é a coisa maior de todas. Na minha época, não tinha passos especiais junto com a bateria, você fazia o que quisesse. Não tinha ensaio, regra. A bateria ensaiava pra não sair do ritmo. Era mais natural.

As rainhas de bateria, as destaques de chão e de carro alegórico não têm a mesma autenticidade das passistas, porém é um recurso de marketing importante para a divulgação das Escolas. Esses cargos vão proporcionar grandes disputas entre as candidatas, envolvendo muitas vezes complicadas intrigas, pois as Escolas de Samba convidam celebridades da televisão e do mundo da moda, deixando de lado as mulheres sambistas pertencentes às comunidades de origem das Escolas, que desde pequenas têm grande participação em sua vida. Muitas dessas sambistas não têm condições financeiras para metamorfosear o corpo a ser apresentado na Avenida tal como é esperado. E muitas rainhas de baterias externas à comunidade da Escola conseguem esses cargos por razões financeiras: o patrocínio direto ou indireto para os figurinos desenvolvidos para os ritmistas -o que atende ao objetivo da Escola de Samba de sempre diminuir seus custos. Faz-se assim aqui o corpo como capital. As metamorfoses apresentadas por algumas das rainhas de bateria nos levam a refletir sobre a estética desejada por uma mulher. A modelo Gracyanne Barbosa16 (Figura 9), quando foi rainha de bateria da Escola de Samba Estação Primeira de Mangueira, no carnaval de 2013, mostrou um corpo escultural na Avenida. O mais surpreendente foi que, minutos após o término do desfile, já estava nas redes sociais a comparação do corpo da modelo com o corpo do personagem de histórias em quadrinho, o Incrível Hulk (Figura 10). Como foi que uma mulher, depois de tantos sacrifícios para atingir o "corpo perfeito", acabou sendo comparada a um personagem mutante, caracterizado por uma radical e sú- bita metamorfose corporal monstruosa? O "corpo perfeito" da modelo foi criticado pelas mulheres por ser comparável a um corpo masculino. $E$ foi considerado pelos homens um corpo modificado, inautêntico, que violava a forma ideal do imaginário feminino. 
O Carnaval parece constituir, na análise do antropólogo Roberto DaMatta (1979), um espaço social especial, voltado para a exibição coletiva, o diálogo gestual e o comentário cultural entre as diversas classes e segmentos componentes da sociedade brasileira. Segundo ele:

O espaço do Carnaval é, assim, o espaço espremido entre a fantasia e a roupa de trabalho, a mulher e a amante, o machão e o homossexual, a riqueza e a pobreza, o dominador e o dominado, a família e a associação voluntária, a igualdade e a hierarquia. Como ocorre nos ritos de passagem na sua fase mais dramática, o Carnaval cria uma realidade que não está aqui nem lá; nem fora nem dentro do tempo e do espaço que vivemos e percebemos como "real" (Damatta, 1979, p. 117).

E finaliza com o comentário de que, justamente por isso, não podemos deixar de viver o mundo carnavalesco como uma realidade que mexe com o nosso imaginário, provocando um conjunto de memoráveis experiências. Um ritual de complexa articulação social para quem está em cima ou em baixo, para quem está em casa ou para quem está na rua, tal como é mostrado numa clássica pintura de Bruegel (Figura 11) (Damatta, 1979).

Viviane Araújo17, rainha de bateria por mais ou menos oito anos da Escola de Samba Acadêmicos do Salgueiro (Figura 12), sempre mostrou na Avenida um corpo considerado perfeito para o carnaval. Incensada como musa por todos os gêneros, é a rainha mais esperada e aclamada no ensaio técnico e no dia do desfile oficial. Viviane Araújo em suas entrevistas declara que é "rata de academia" e que o corpo é o carro chefe para os seus trabalhos.

Em 2014, participou da telenovela Império, exibida pela Rede Globo, em que interpretou uma mulher do povo, manicure (Figura 13). Por estar com o corpo muito "grande" (que, com a lente das câmeras, aumentaria muito mais, ficando sem a forma desejada pelo diretor da telenovela), foi obrigada a perder quatro quilos e afinar a silhueta -para então assumir a personagem. E, para voltar a se apresentar na Avenida, no posto de rainha de bateria, teve que voltar ao corpo anterior. Esse é o chamado "efeito sanfona", em que o corpo deve sofrer diversas metamorfoses para se adequar a sucessivas propostas de trabalho.

Natália Casassola (Figura 14), participante, em 2008, do reality show televisivo Big Brother Brasil 8, após ser convidada para desfilar na Escola de Samba Acadêmicos da Rocinha, no Rio de Janeiro, como destaque, começou por intensificar a preparação do corpo para o desfile. Mas, em entrevista ao site www.revistaquem.globo.com, declarou: "Vou para a Avenida como uma mulher normal, não vou desfilar parecendo um pônei". A modelo fazia referência aos corpos definidos e coxas bem torneadas apresentadas na Avenida, que são às vezes passíveis de comparação com os de um musculoso cavalo (Figura 15).

O destaque geralmente é um componente isolado, que vem vestido com um figurino rico, sobre o "queijo", no carro alegórico ou no chão. Esta posição é geralmente ocupada por mulheres ou homossexuais. Roberto DaMatta (1979, p. 102), sobre o destaque de carro alegórico explica que: "a escola de samba é uma organização coletiva, mas que permite o destaque, essa forma extremada de individualidade".

Os figurinos desenhados pelo carnavalesco não são necessariamente designados para um determinado gênero e sim para o corpo que irá vestir. Para um profissional de modelagem como eu, essa característica foi a que mais me despertou a atenção no mundo do carnaval: como desenvolver para os mais diferentes corpos, independente do gênero e de suas modificações, as vestimentas adequadas. 
Há, por exemplo, corpos masculinos que irão vestir um figurino concebido dentro do enredo para uma personagem feminina. As proporções do corpo masculino são normalmente bem diferenciadas do corpo feminino, e essas diferenças terão que ser nesse caso metamorfoseadas na modelagem, usando recursos de amarrações para afinar a cintura, enchimentos para os seios, e recortes diversos que ajudam na adaptação. Os destaques que enfrentam uma situação desse tipo também têm toda uma preocupação com o próprio preparo corporal, recorrendo aos artifícios já mencionados.

As travestis, por meios de caminhos e processos próprios, também conquistaram um espaço no carnaval. Um espaço que se caracteriza por ser dúbio, no qual estão presentes, ao mesmo tempo, os preconceitos, a exclusão e o caráter exótico -por um lado-, e o encanto, a fantasia e a sedução que caracterizam, como um todo, esse grupo no carnaval. Como comenta Richard Parker, a respeito do Brasil (1991, apud Beneditti, 2005):

Os valores atribuídos ao masculino e feminino seja flexíveis e pouco delimitados, construindo um quadro mais "permissivo" no que diz respeito aos gê- neros e à sexualidade e seus usos, garante possibilidades para que os desejos de transformação e construção do feminino sobre um corpo masculino sejam realizados. Assim, as travestis, ao fabricar formas e contornos femininos nos seus corpos, estão construindo seu próprio gênero, seus próprios valores relacionados ao feminino e ao masculino, que constituem, em suma, os processos de fabricação dos sujeitos. (Parker, 1991, apud Beneditti, 2005, pp. 129-130).

Todos os gêneros que se encontram dentro do circuito das Escolas de Samba, no dia do ensaio técnico18, são motivados pelos diretores da Escola a participarem da festa; mas é grande o incentivo para que os homens em geral, homossexuais ou não, se transformem em personagens femininos e se apresentem da forma mais diva ou caricata possível. O objetivo é mostrar para o público presente nas arquibancadas que aquela Escola de Samba é a mais animada e festiva na Passarela do Samba. Esse ensaio é o momento mais caracteristicamente carnavalesco dentro do calendário oficial do carnaval, em que o grito de guerra é a diversão. É o dia de "soltar a franga", soltar a personagem feminina que está presa supostamente nos corpos masculinos. A liberalidade da festa coloca em cena práticas e valores nem sempre aceitos no tempo comum, da vida cotidiana. Tudo em termo de fantasia é permitido naquele dia. É o verdadeiro dia da transgressão e da liberação dos preconceitos, cumprindo com o que DaMatta enfatiza como sendo a maior característica do Carnaval: um momento em que as regras, rotinas e procedimentos convencionais são modificados ou metamorfoseados, reinando a livre expressão dos sentimentos e das emoções, quando todos podem e devem se manifestar individualmente (DaMatta, 1979). Pode-se dizer que este é o momento mais esperado pelos homens e homossexuais que pertencem às classes menos favorecidas dentro da Escola. Muitos deles não têm condições de participar no dia do desfile oficial, seja por falta de condições financeiras para investir na produção do figurino ou por falta de apadrinhamento para garantir o patrocínio do figurino (pelo carnavalesco, diretor, presidente de ala ou o dono de ateliê). James Green (2000) acrescenta que, para certos homossexuais, travestir-se durante o carnaval é também menos uma inversão do que uma tentativa de assumir uma desejada forma feminina. E completa, que ao adotar as roupas, a maquiagem e as performances femininas, esses homens vivenciam suas próprias fantasias e desejos femininos imitando meticulosamente a norma social. O carnaval é considerado por eles o palco maior para essa encenação, mais importante que as festas e eventos entre os amigos e grupos do mesmo time (Green, 2000).

Em 1994 e 1995, a Escola de Samba Acadêmicos do Grande Rio levou para a Avenida o bailarino José Reinaldo de Farias (Figura 16) à frente da bateria, como "rei de bateria". Esse posto até então tinha sido 
somente ocupado por mulheres. O bailarino revelou depois que sofreu muitos preconceitos com os próprios passistas do carnaval, por estar ocupando um posto destinado às mulheres.

Em 2015 o promoter David Brazil (Figura 18) veio a ser coroado "rei da bateria", ao lado da atriz Susana Vieira. A Escola é conhecida por ousar, e não ficar presa às "regras" convencionais da sociedade. Em entrevista à jornalista Eliane Santos, no site www.ego.globo.com.br, David Brazil declarou que fez uma revisão geral no corpo: fez lipoescultura no peito, nas axilas e no abdômen, corrigiu uma cirurgia de hérnia umbilical e fez um implante capilar com 10 mil fios (Figura 17).

Danilo Dias (Figura 19), médico que cuidou da metamorfose do promoter, revelou que tirou gordura do próprio paciente para enxertar no peito, dando um contorno de músculo. O que fez foi deixar seu paciente como se estivesse musculoso, pelo efeito da lipoescultura. Finalizou dizendo que "ele vai ficar aqui com a gente no Spa para fazer terapia capilar, massagens e drenagens com fisioterapeutas. Vai arrasar no carnaval".

David Brazil declarou para a jornalista, um dia após a cirurgia:

"Ai, estou viva, sabe, mas quase não sobrevivo. Doutor Danilo disse que retirou $360 \mathrm{ml}$ de gordura dos meus peitos. Quase uma Danielle Winits. E mais um litro de gordura da região da barriga. Agora, estou pronta para brilhar no Carnaval".

Como se pode observar na Figura 18, a fantasia desenvolvida para o promoter cobria todo o corpo. Todo o procedimento teve, portanto, como objetivo apenas marcar a silhueta.

\section{Considerações finais}

A reflexão sobre o corpo e o seu uso como produto na moda ou no Carnaval, independentemente do gênero, pelas mídias, principalmente a televisiva, impõe a consideração de que ele é vendido para o Brasil e para o mundo como um dos "produtos" que mais assumem valores midiáticos no cenário contemporâneo, seja na passarela de moda ou na Passarela do Samba. O corpo é o elemento crucial de marketing para esse tipo de negócio. Os valores criados pela sociedade não se limitam à roupa e à sua função de proteção, de pudor ou de distinção do indivíduo na sociedade ou grupo ao qual pertence. A moda, pelo que significa em termos de metamorfose do corpo, é considerada uma forma de linguagem, que evidencia o período histórico envolvido, coma mudança corporal característica de cada época.

A contemporaneidade gera novos modelos estéticos e comportamentais do ser humano. E o que ganham esses corpos depois de tantas modificações? O que é visto nas passarelas é que o indivíduo se considera "poderoso", por ter o corpo mais pulcro do Carnaval ou da passarela. É um momento mágico -os famosos quinze minutos de fama- que desaparece logo que o Carnaval ou o desfile acabam.

A análise aqui apresentada é uma reflexão sobre a reformulação intencional, artificial, do corpo humano, motivando novas expressões estéticas no âmbito social. O indivíduo contemporâneo não tem uma identidade garantida pelo seu nascimento ou criação infantil -tudo pode ser modificado.

O que é considerado belo não deveria residir, na verdade, apenas no ansiado corpo perfeito, mas no seu significado existencial mais abrangente. Por um lado, é preciso reconhecer que as atuais possibilidades técnicas 
de vestuário e modificação corporal permitem uma escala muito mais ampla de alternativas para todas as pessoas, ensejando processos de satisfação de desejos impensáveis há pouco tempo atrás. Por outro lado, porém, há também o risco de uma grande irresponsabilidade do ser humano, independentemente do gênero, com o seu próprio corpo, achando que possa ser invulnerável, negligenciado de cuidados, submetido a todos os riscos e excessos possíveis, para atender às mais variadas fantasias pessoais. Provavelmente, o ideal seria que se viesse a buscar um equilíbrio nessas fantásticas buscas de metamorfose dos próprios corpos. A moda e o carnaval continuarão a ser lugares privilegiados para fazê-lo.

Notas

1. De acordo com a Organização Mundial da Saúde (OMC), uma pessoa é considerada magra se o seu IMC, que é a relação entre peso e altura, for inferior a 18,5. A agência da ONU estabelece distinções entre magreza leve (entre 17 e 18,5), moderada (entre 16 e 17) e severa (abaixo de 16).

2. O binário de gênero é a classificação do sexo e do gênero em duas formas distintas, opostas e desconectadas de masculino e feminino; homem e mulher. É um dos tipos gerais de sistemas de gênero. Como um dos princípios centrais do cissexismo, pode descrever o tabu que desencoraja as pessoas a misturar ou atravessar os papeis sociais de gênero, ou de identificarem-se como uma terceira (ou outra) identidade de gênero, completamente fora da binária homem-mulher. Pode, ainda, representar a discriminação que estigmatiza pessoas intersexo e transgêneras, especialmente aquelas cujo gênero não é binário - isto é, que não identificam-se normalmente dentro do binário de gênero.

3. Os primeiros estudos científicos sobre linguagem corporal foram feitos por Charles Darwin e publicadas no livro "A expressão das emoções em homens e animais". Darwin defendia que os mamíferos demonstravam suas emoções através de expressões faciais. A linguagem corporal foi uma das primeiras formas de comunicação humana e continua sendo uma das mais fortes e expressivas. A Linguagem corporal vem sendo utilizada há milhões de anos e está relacionada principalmente ao sistema límbico (mesencéfalo), a segunda estrutura mais primitiva do nosso cérebro.

4. Componente do vestuário feminino utilizado, sob outra peça de roupa que pode ser um vestido, uma camiseta etc, para sustentar ou revestir os seios.

5. A barriga negativa é desejo de mulheres no mundo inteiro desde que a top Candice Swanepoel -uma das mais badaladas Angels da Victoria's Secret- postou uma foto em seu Instagram ostentando uma barriguinha côncava (com uma certa curva para dentro).

6. Na silhueta Triângulo Invertido temos ombros e peitos largos, braços com músculos bem definidos e quadris e cintura estreita, ou seja, a parte superior é maior que a parte inferior do corpo.

7. Moda é a maneira de se apresentar ou o costume social mais predominante em um determinado grupo em um determinado momento. É uma palavra muito usada para designar uma forma específica de se vestir comum ou apreciada por um determinado conjunto de pessoas. Estilos diferentes de moda expressam características de grupos sociais distintos. 
8. Segundo Sant'Anna (2005), a partir da segunda metade do século XX, a sociedade passou a acolher uma profunda aversão à gordura. O que era até então sinônimo de saúde e até mesmo critério de beleza redundou no seu inverso, numa patologia.

9. Madri foi a primeira capital europeia a adotar medidas contra a anorexia no meio da moda, proibindo desde 2006 modelos com um IMC inferior a 18. Fora da Europa, Israel adotou em 2012 a "lei do photoshop", em referência ao nome do software de tratamento de imagem. As modelos israelenses também precisam ter um IMC superior a 18,5 para poder trabalhar. Itália, Chile e Bélgica adotaram medidas semelhantes.

10. avant-garde |àvã gárde| (palavra francesa) substantivo masculino. 1) Agente, grupo ou movimento intelectual, artístico ou político que está ou procura estar à frente do seu tempo, relativamente a .ações, .ideias ou experiências. VANGUARDA adjetivo de dois gê- neros. 2) Que está ou procura estar à frente do seu tempo, relativamente a .ações, .ideias ou experiências. = VANGUARDISTA "avant-garde", in Dicionário Priberam da Língua Portuguesa [em linha], 2008-2013, https://www.priberam.pt/dlpo/avant-garde [consultado em 30-052017].

11. http://www1.folha.uol.com.br/ilustrada/2015/09/1678464-modelos-com-down-albi nismo-e-vitiligo-sao-apostanas-passarelas.shtml

12. Esse conceito é definido pelo Centro de Equidade de Gênero da Universidade da Califórnia em Berkeley como: uma pessoa cuja identidade de gênero não é nem homem nem mulher, está entre os sexos ou além, ou é uma combinação de gêneros. Essa identidade é geralmente uma reação à construção social do sexo, aos estereótipos de gênero e ao sistema binário de gênero. Algumas pessoas não binárias se colocam sob o guarda-chuva dos transgêneros, enquanto outras não. Disponível em: https://oglobo.globo.com/sociedade/ tecnologia/nao-binarios-publicam-selfies-nas-redes-para-mostrar-que-significa-essa -identidade-de-genero14383736 - acessado em 20/04/2017.

13. Androginia refere-se a dois conceitos: a mistura de características femininas e masculinas em um único ser, ou uma forma de descrever algo que não é nem masculino e nem feminino. A pessoa que se sente com alguma combinação de características culturais, tanto masculinas (andro) quanto femininas (gyne) é quem se identifica e se define como tendo níveis variáveis de sentimentos e traços comportamentais que são tanto masculinos quanto femininos. Disponível em: https://pt.wikipedia.org/wiki/Androginia - acessado em 23/03/2016.

14. De acordo com Sant'Anna (2005), a vaidade excessiva, o cuidar com corpo de forma demasiada é modo de reafirmar a própria personalidade e de se sentir feliz ao ver a sua imagem divulgada nos meios midiáticos de forma sensual.

15. A função da rainha de bateria é a de auxiliar o mestre de bateria no comando da ala de percussão, levando animação para os componentes, com um belo balé coreografado e sensualidade para todo o público presente na passarela do samba.

16. Gracyanne é famosa por ter feito diversos ensaios sensuais para revistas masculinas e sites especializados. Em janeiro de 2007 foi capa da revista Playboy e em dezembro de 2011 foi capa da revista Sexy, mostrando a grande mudança que seu corpo sofrera ao longo dos anos com o ganho muscular e dieta. 
17. Modelo, bailarina e atriz, desfila no carnaval brasileiro desde 1995. Em 2002, estreou como rainha de bateria da Escola de samba carioca Mocidade Independente de Padre Miguel. Desde o carnaval de 2008, é rainha de bateria da Escola de Samba Acadêmicos do Salgueiro. Ela também foi coroada rainha dos gays do Brasil em 2008 durante a $12^{a}$ edição da Parada do Orgulho GLBT, realizada em São Paulo. Em 2012, participou do reality show A Fazenda 5, da Rede Record, e venceu o programa. Viviane recebeu na ocasião um prêmio de dois milhões de reais. Em 2013, foi eleita "Rainha das Rainhas" pelo tradicional bloco de carnaval Cacique de Ramos.

18. "Ensaio técnico" é o treino final que acontece dias antes do desfile oficial das Escolas de Samba.

\section{Referências}

Alzer, Luiz André (1971). Almanaque anos 80 / Luiz André Brandão França Alzer, Mariana Costa Claudino. Rio de Janeiro: Ediouro, 2004.

Butler, J. P. (2003). Problemas de gênero: feminismo e subversão da identidade. Rio de Janeiro: Editora Record.

Benedetti, M. R. (2005). Toda feita: o corpo e o gênero das travestis. Rio de Janeiro: Garamond.

Bento, B. (2006). A reinvenção do corpo: sexualidade e gênero na experiência transexual. Rio de Janeiro: Garamond.

Cohen, D. (2015). Alinguagem do corpo: o que você precisa saber. Tradução de Daniela Barbosa Henriques. 10.ed. Petrópolis,RJ: Vozes.

Da Matta, R. (1979). Carnavais, Malandros e Heróis para uma sociologia do dilema brasileiro. Rio de Janeiro: Editora ZAHAR.

Fry, P. (1982). Para inglês ver - Identidade e Política na Cultura Brasileira. Rio de Janeiro: Editora ZAHAR.

Goldenberg, M. (2005). Gênero e corpo na cultura brasileira. Psicologia Clínica, Rio de Janeiro, v.17, n.2, p. 6580. (2010) (org.). O corpo como capital: gênero, sexualidade e moda na cultura brasileira (2ed.). São Paulo: Estação das Letras e Cores.

Green, J. N. (1915). Além do carnaval. A homosexualidade masculina no Brasil do século XX. Tradução Cristina Fino e Cássio Arantes Leite. São Paulo: Editora UNESP, 2000.

Grave, M. de F. (2004). A modelagem sob a ótica da ergonomia. São Paulo: Zennex.

Lurie, A. (1997). A linguagem das roupas. Tradução de Ana Luiza Dantas Borges. Rio de Janeiro: Rocco. Machado, C. J. S.; Santiago, I. M. F. L. e Nunes, M. L. S. (2010) (orgs.). Gêneros e práticas culturais: desafios históricos e saberes interdisciplinares [online]. Campina Grande: EDUEPB. 256 p. ISBN 978-85-7879-038-7. 
Available from Sci ELOBooks .- acessado em 19/02/2017.

Oliveira, A. C. G. de A.; Viana, A. J. B. e Sousa, E. S. S. (2013). O corpo intersexual como desconstrução dos gêneros inteligíveis: uma abordagem sócio-jurídica - Portal de Conferências do Laboratório de Tecnologias Intelectuais - LTi, $17^{\circ}$ Encontro Nacional da Rede Feminista Norte e Nordeste de Estudos e Pesquisa sobre a Mulher e Relações de Gênero. Disponível em: http://www.ufpb.br/evento/lti/ocs/index.php/17redor/17redor/paper/ viewFile/87/47 - acessado em 10/12/2016.

Papalia, D. E.; Olds, S. W. (2000). Desenvolvimento humano. (7ed.). Porto Alegre: Artes Médicas Sul.

Picazio, C. (1998). Sexo secreto: temas polêmicos da sexualidade. Claudio Picazio; com a colaboração de Eduardo Bittencourt, Rogério Brugnera e Alexandre R. Araujo. São Paulo: Summus.

Sant'anna, D. B. (2005). Transformação do corpo: controle de si e uso dos prazeres.Imagens de Foucault e Deleuze ressonâncias nietzschianas. (2ed.) Rio de Janeiro: DP\&A. p. 99-110.

Reis, N. e Pinho, R. (2005). Gêneros não-binários: identidades, expressões e educação. A matéria publicada nesse periódico é licenciada sob forma de uma Licença Creative Commons - Atribuição 4.0 Internacional .>http://creativecommons.org/licenses/by/4.0/" - Disponível em file://C:/Users/Croa\%20Modelagem/Downloads/7045-33012-1-PB. pdf - acessado em 05/03/2017.

Ubim, E. Desfile de histórias. Revista do jornal O Globo. Pág. 24-31. 09/11/2014.

Ribeiro, C. Folia a bordo. Revista do jornal O Globo. Pág. 36-42. 13/09/2015.

Rondinelli, P. "Carnaval, Corpos e Poder”; Brasil Escola. Disponível em . Acesso em 20 de maio de 2017.

Villaça, N. \& Castilho, K. (2006) (org.). Plugados na moda. São Paulo: Editora Anhembi Morumbi. Vários colaboradores.

Web sites

https://dicionariodoaurelio.com- acessado em 28/09/2016.

http://oglobo.globo.com/ela/moda/manter-as-medidas-passar-horas-em-pe-fazem-partedo-lado-duro-da-carreirade-modelo-de-prova-16954186 - acessado em 16/01/2016.

http://brasilescola.uol.com.br/carnaval/rainha-bateria.htm - acessado em 28/09/2016.

http://g1.globo.com/rio-de-janeiro/carnaval/2014/noticia/2014/02/nao-sabia-o-sambalembra-monique-evans-1rainha-de-bateria-ha-30-anos.html - acessado em 28/09/2016.

http://epoca.globo.com/sociedade/bruno-astuto/noticia/2017/03/lutei-muito-para-estaraqui-diz-top-trans-quedesfilou-de-biquini-na-spfw.html - acessado em 30/09/2016. 
http://vogue.globo.com/moda/moda-news/noticia/2016/10/ronaldo-fraga-apresentadesfile-so-com-modelostrans.html - acessado em 05/10/2016.

http://revistaquem.globo.com/Carnaval-2016/Rio-de-Janeiro/noticia/2015/11/nataliacasassola-sobre-carnaval2016-nao-vou-desfilar-parecendo-um-ponei.html - acessado em 10/12/2017.

https://oglobo.globo.com/cultura/franca-proibe-modelos-com-magreza-excessiva -15775537 - acessado em 20/05/2017.

http://br.rfi.fr/franca/20170505-franca-decreta-multa-contra-anorexia-de-modelos-e-im poe-mencao-de-fotoretocada - acessado em 09/05/2017.

http://brasil.elpais.com/brasil/2015/04/03/cultura/1428076511_471564.html - acessado em 10/05/2017.

http://ego.globo.com/carnaval/2017/noticia/2016/12/david-brazil-enxertou-gordura-nopeito-vai-parecermusculoso.html - acessado em 30/01/2016.

https://oglobo.globo.com/sociedade/tecnologia/nao-binarios-publicam-selfies-nas-redespara-mostrar-quesignifica-essa-identidade-de-genero-14383736\#ixzz4iF9oBDI8 Stest - acessado em 10/05/2017.

Resumen: El objetivo del siguiente artículo es presentar un estudio de los desafios de la forma de los cuerpos generados en el ámbito de la Moda y el Carnaval Carioca. El cuerpo es un vehículo esencial de la existencia humana en cualquier cultura y viene convirtiéndose cada vez más crítico en el mundo contemporáneo. El ser humano existe y participa de los grupos sociales a través de su cuerpo. Independientemente de su género, el cuerpo es mucho más que un conjunto de músculos y huesos, es también la ropa y el estilo que lo decoran, es la imagen que por medio de él es producida; constituyéndose en un desafio permanente para los profesionales de la moda. El dualismo de sexo y género constituye una dimensión crítica de dichos procesos.

Palabras clave: Cuerpo - Género - Moda - Carnaval - Metamorfosis - Comunicación - Lenguaje corporal.

Abstract: The aim of this article is to analyze the challenges of form in the genderized bodies present in the world of fashion and carnival in Rio de Janeiro. The body is an essential dimension of human existence in any culture, and it has been growing more and more critical in the contemporary world. The human being exists and participates in social groups through his body. The body is much more than a bunch of muscles and bones, for any gender; it is also the garments and the style that it bears, and the image it projects -being a permanent challenge for fashion specialized workers. The dualism of sex and gender is a most critical dimension of all those processes.

Key words: Body - Gender - Fashion - Carnival - Metamorphosis - Communication - Body language.

[Las traducciones de los abstracts fueron supervisadas por el autor de cada artículo] 
